\title{
Immunoexpression of gemins 2 and 4 in the rat spinal cord. Is the SMN complex a new target in investigations of sporadic amyotrophic lateral sclerosis pathogenesis?
}

\author{
Janina Rafałowska', Dorota Sulejczak², Roman Gadamski', Dorota Dziewulska ${ }^{1,3}$ \\ ${ }^{1}$ Department of Experimental and Clinical Neuropathology, Mossakowski Medical Research Institute, PAS, Warsaw, ${ }^{2}$ Department \\ of Experimental Pharmacology, Mossakowski Medical Research Institute, PAS, Warsaw, ${ }^{3}$ Department of Neurology, Medical University \\ of Warsaw, Poland
}

\begin{abstract}
Sporadic amyotrophic lateral sclerosis (SALS) is a neurodegenerative disease leading to degeneration and loss of motoneurons in different structures of the nervous system. Although aetiology of the disease is unknown, it is hypothesized that the survival motor neuron (SMN) protein which protects motoneurons in spinal muscular atrophy, may play a similar role in ALS. Relatively little is known about normal expression and functions of the SMN complex compounds, i.e. $S M N$ protein and the related gemins. Therefore, we have decided to examine the physiological expression of SMN and gemins 2 and 4 in spinal cords of healthy Wistar rats at different age using immunofluorescence and immunohistochemical methods. Our study revealed that (1) in rat spinal cord neurons, the immunoexpression of SMN and gemins 2 and 4 is present through the whole animal lifespan although the reactive cells reveal different intensity of the immunolabeling, (2) both SMN and gemin 2, and SMN and gemin 4 are present in the same motoneurons, (3) immunoexpression of gemin 2 and 4 decreases slightly with aging.
\end{abstract}

Key words: SMN, gemin, ALS, rat.

\section{Introduction}

Mutation of the telomeric form of the SMN gene $(\mathrm{SMN}-1)$ causes spinal muscular atrophy (SMA). As a result of the mutation (deletion of the exons 7,8 of $S M N-1$ gene) delayed development of skeletal muscles and degeneration of motoneurons in the spinal cord and brain stem are observed. Clinically, there are three forms of SMA of different severity. In the early infantile form (form I, Werdig-Hoffman disease), clinical symptomatology is the most severe and quickly leads to patient disability and death. In forms II and III, the course and symptomatology of the disease are more benign. Encoded by the SMN gene, the survival motor neuron (SMN) protein together with other proteins forms the SMN complex of a key importance for the motoneuron function. The SMN complex closely cooperates with many other multifunctional proteins, including small nuclear ribonucleoproteins (snRNAs), and - acting frequently with uridine - plays a role in the $S M N$ gene splicing process $[1,8,9,11]$. Except functions in the assembly of smRNAs it probably also par- 
ticipates in the assembly, metabolism, and transport of other classes of ribonucleoproteins.

Apart from the SMN protein, the SMN complex contains several other proteins including gemin 2 and gemin 4 . Gemin 2 is present in the cell cytoplasm, processes [23], and in gems - small structures localized in the nucleus. Gems are similar in size and number to Cajal bodies and play a role in gradual maturation of RNA. In the SMN complex, gemin 2 binds directly to the SMN protein. A small complex composed only of SMN and gemin 2 represents its inactive form whereas the high molecular form containing SMN, gemin 2, 3 and 4 is an active form that can bind substrates [17]. Gemin 2 plays a role in stabilization of the SMN complex [16], in export of smRNAs from the nucleus, and in their assembly in the cytoplasm [12].

Gemin 4, similarly to gemin 2, is localized in the cytoplasm and nucleus. Besides location in nucleolar gems, the protein is also present in nucleoli. Such localization of gemin 4 suggests that the SMN complex may also function in preribosomal RNA processing or ribosome assembly. Unlike gemin 2, gemin 4 does not bind with the SMN protein directly but interacts with it via gemin 3 [2].

Formerly published few studies on various experimental models $[6,10]$ have not answered how long the SMN complex is active in individual life. Our previous investigations on healthy rats showed preserved immunoexpression of SMN and gemin 3 during the whole animal lifespan [19]. In the double staining immunofluorescent method we also demonstrated that both SMN and gemin 3 were expressed in the same motoneurons. The aim of the present study was to attempt to answer whether: (1) SMN and gemin 2, and SMN and gemin $4-$ similarly to SMN and gemin $3-$ are expressed in the same motoneuron; (2) immunoexpression of gemins 2 and 4 remain unchanged during the rat lifespan; and (3) whether aging influences immunoreactivity for gemins 2 and 4 .

\section{Material and methods}

The experimental material consisted of spinal cords obtained from 27 adult male Wistar rats. Rats were divided into 9 groups composed of 3 rats at age of $1,10,20,30,60,150,200,250$ and 350 days. All animal using procedures were accepted by the $4^{\text {th }}$ Local Animal Experimentation Ethics Committee and were in agreement with the European Union rules on the care and use of laboratory animals.
Animals were anaesthetized with Nembutal (20 mg/ kg b.w., i.p.) and perfused through the ascending aorta with $0.9 \% \mathrm{NaCl}$ in $0.01 \mathrm{M}$ sodium-potassium phosphate buffer $\mathrm{pH} 7.4$ and then with 4\% formaldehyde in $0.1 \mathrm{M}$ phosphate buffer $\mathrm{pH}$ 7.4. Next, the laminectomy was performed and spinal cords were removed. The material was soaked in $4 \%$ formaldehyde for $2 \mathrm{~h}$, embedded in paraffin, and cut on the $40 \mu \mathrm{m}$-thick sections.

On glass-mounted sections of spinal cords, immunohistochemistry for light microscopy was executed according to avidin-biotin-peroxidase method. Material was dehydrated in alcohol, pretreated $3 \times 10 \mathrm{~min}$ in microwave in $10 \mathrm{mM}$ citrate buffer $\mathrm{pH} 6.0$ for antigen retrieval, and labelled with primary antibodies (Ab) against SMN (Santa Cruz Biotechnology, 1 : 250), gemin 2 (Santa Cruz Biotechnology, 1 : 500), and gemin 4 (Santa Cruz Biotechnology, 1 : 1000) using Goat F(ab)2 Fragment anti-mouse lgG-biotin (Beckman Counter, $1: 1500$ ) and Goat F(ab)2 Fragment anti-rabbit IgG-biotin (Beckman Counter, $1: 1500$ ), respectively. The diaminobenzidine (DAB) was used as a chromogen.

For fluorescent microscopy, double immunofluorescent reactions for SMN and gemin 2, and for SMN and gemin 4 were performed. The first step of the procedures was the same as for single immunohistochemistry but then simultaneous incubation with polyclonal rabbit anti-SMN Ab and one of two primary antibodies: monoclonal mouse anti-gemin $2 \mathrm{Ab}$ or monoclonal mouse anti-gemin $4 \mathrm{Ab}$ was performed. Following the incubation, the sections were washed and incubated for $1 \mathrm{~h}$ at $37^{\circ} \mathrm{C}$ with secondary antibodies: goat anti-mouse Alexa Fluor 594 (Invitrogen - Molecular Probes, $1: 100$ ) and goat anti-rabbit Alexa Fluor 488 (Invitrogen - Molecular Probes, 1 : 100).

Specificity of the immunostainings was verified by the execution of the "negative control" staining, in which the procedure with the primary antibodies was omitted in the incubation mixture.

The labelled material was analyzed and captured with an Optiphot-2 Nicon microscope (Japan) equipped with the appropriate filters and a DS-L1 Nicon camera (Japan). For the analysis of immunostaining, image processing software IPP+ (Image Pro Plus) was used. Surface plot profiles were performed from selected sections representing each investigated time point. Blue colour of hematoxylin counterstaining was removed electronically from the analysis. At the plots, the colour of each pixel indicates the level of intensity of the immune reaction. 


\section{Results}

Results of our study indicate that both gemin 2 and gemin 4 are expressed during the whole lifespan of a rat but in different intensity. In an early postnatal period (up to 10 days of life) spinal cord neurons were small, and only weak immunoreactivity for the analyzed gemins was observed (Figs. 1 and 2). The level of the im- munosignal for gemin 2 was generally weaker than that observed for gemin 4. In that period, immunoreactivity for the investigated proteins was also seen in astroglia. In rats at the age from 20 to 150 days, more intense reaction for gemins 2 and 4 in the motoneurons was seen but the signal was unequal within the individual cells and varied from heavy to weak (Figs. 1 and 2). At 350 day of rat lifespan the level of immunoexpression

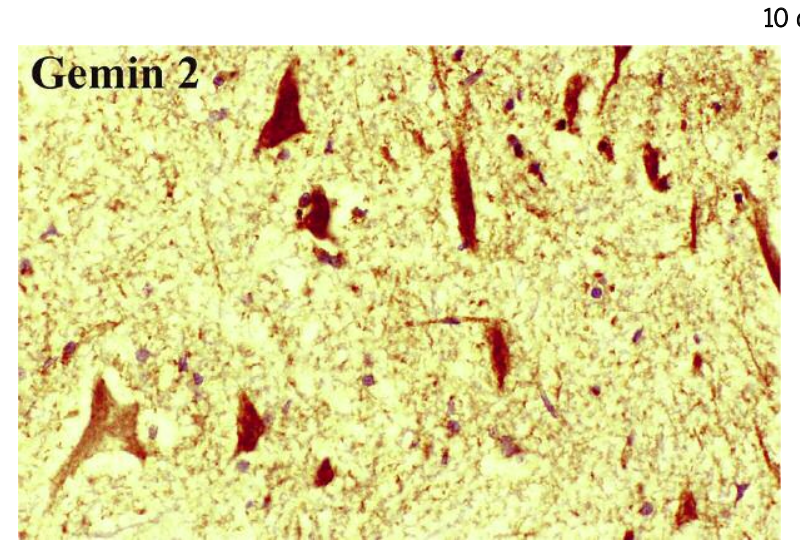

10 days

150 days
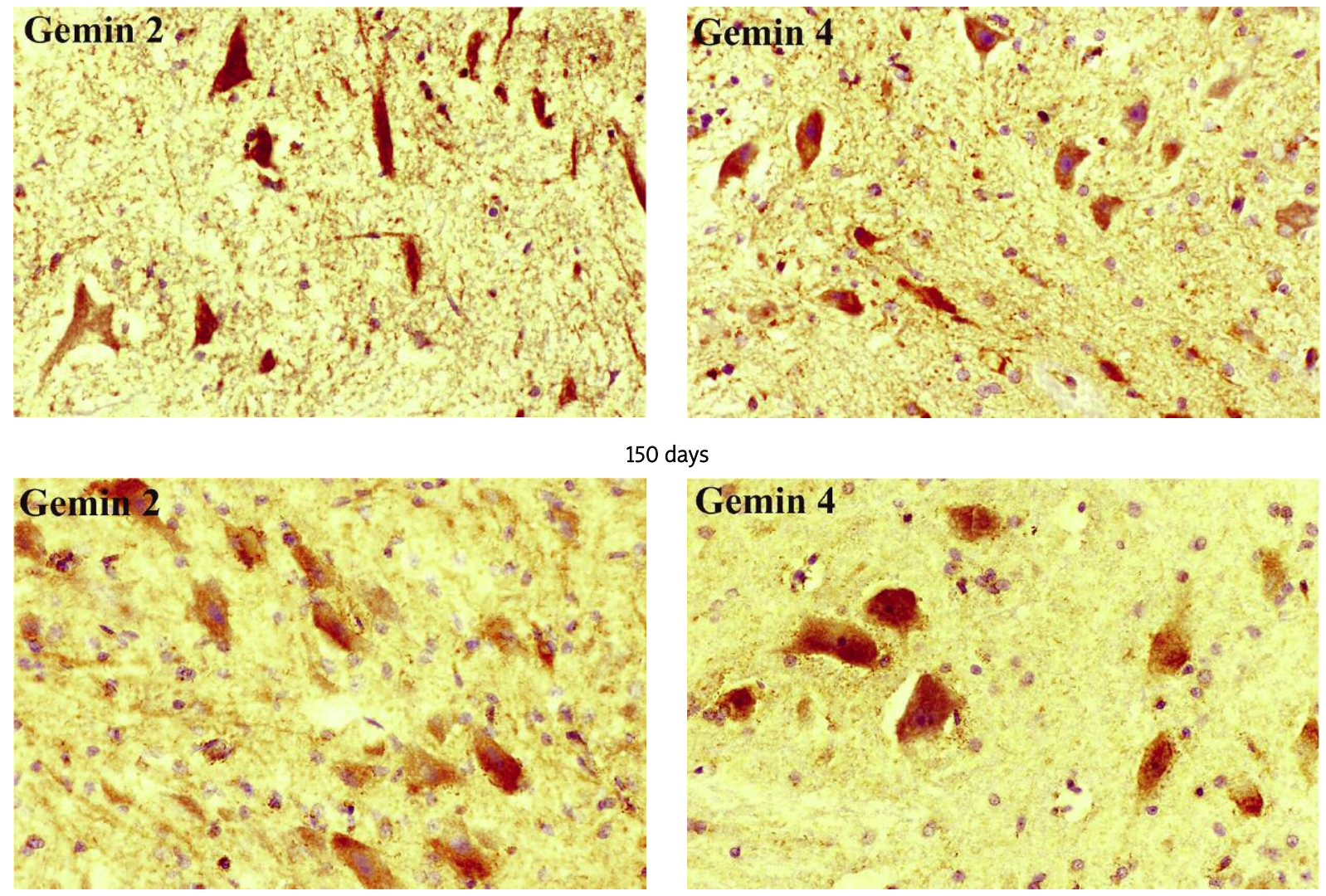

350 days
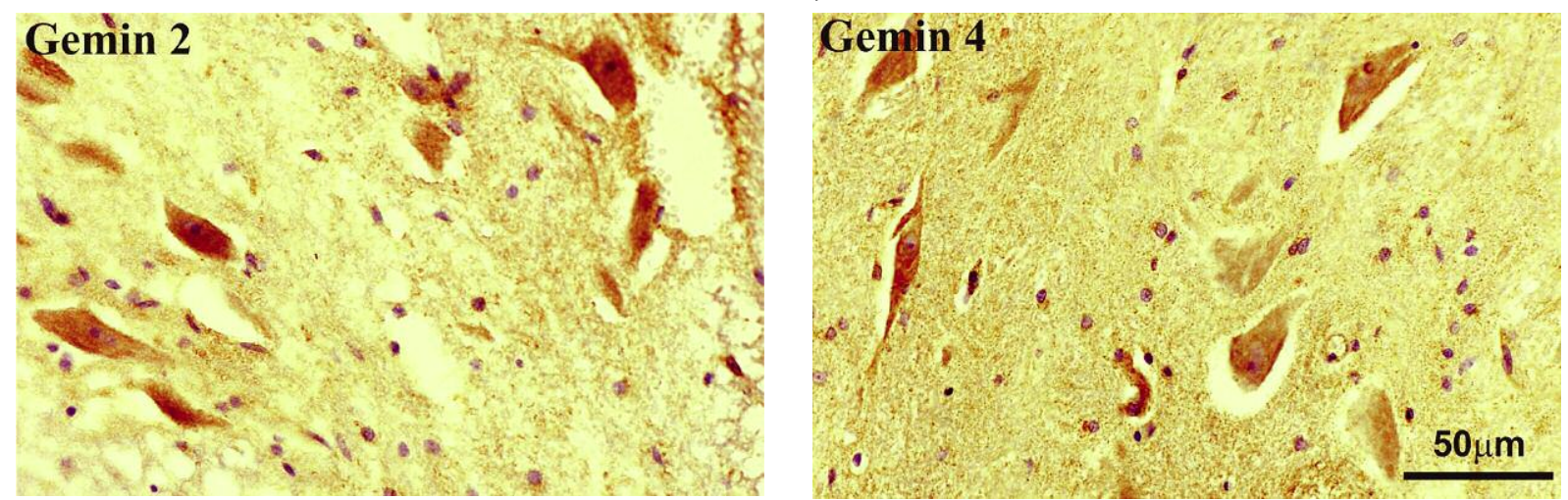

Fig. 1. Immunoreactivity for gemins 2 and 4 in healthy rats at different time points of the animal lifespan. Note the different level of the immunostainings in individual neurons. 

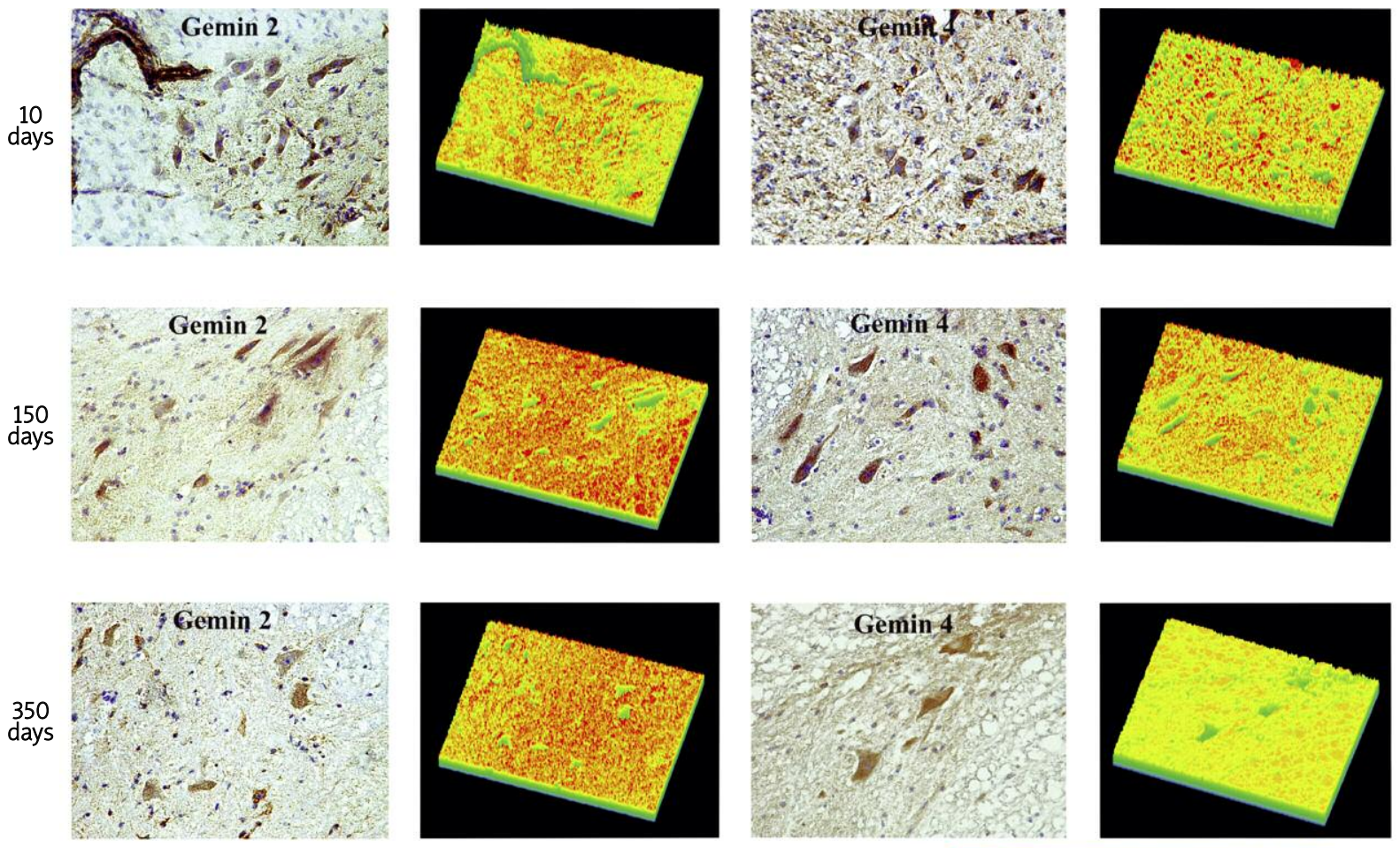

LEGEND:

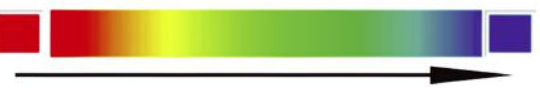

Fig. 2. Surface plot profiles of the selected sections analyzed in pseudocolours. Visible different intensity of the immunosignals in DAB staining.

of both gemins seems to be weaker than in the earlier time points. Similarly to previous observations, the stained motoneurons showed various intensity of the immunosignal, and some of them even demonstrated a negative reaction for the labelling to gemin 2 and 4 (Figs. 1 and 2).

A double staining technique for immunofluorescence revealed the colocalization of SMN protein with gemin 2 and gemin 4 within individual spinal cord neurons (Figs. 3 and 4).

\section{Discussion}

Our experimental study on rats at different age revealed that - similarly to gemin 3 [19]-gemins 2 and 4 are expressed in the same motoneurons as SMN protein. Since the immunoreactivity for the investigated proteins was observed in all examined animals it suggests that in healthy rats the SMN complex is active from the animal birth to its death. Although the immunolabeling for gemins 2 and 4 was various in different neurons and even some of them were immu- nonegative, general results of the immune reactions in young and old animals showed slightly decreased immunoreactivity for the investigated gemins in old rats. Therefore, our investigations imply that aging probably has only a little influence on the expression of the investigated proteins.

Gemins 2 and 4 as compounds of the SMN complex may play a role in SALS pathogenesis. Their participation seems to be reasonable because aberrant RNA processing is regarded as one of the molecular mechanisms of the disease, similarly to axonal transport defects, glutamate excitotoxicity, mitochondrial dysfunction or deficient protein quality control. But the relationship between the SMN complex and SALS has not been established yet. Investigations revealed that an increased number of SMN gene copies can be a risk factor for SALS [3]. On the other hand, results of the experimental studies on SMA and FALS indicate that presence of the SMN protein makes a course of these diseases more benign $[13,24]$. A wild allele of SMN genes plays a role in genetics of SALS [4]. In a mouse model of ALS, deficiency of the SMN gene 


\section{0 days}
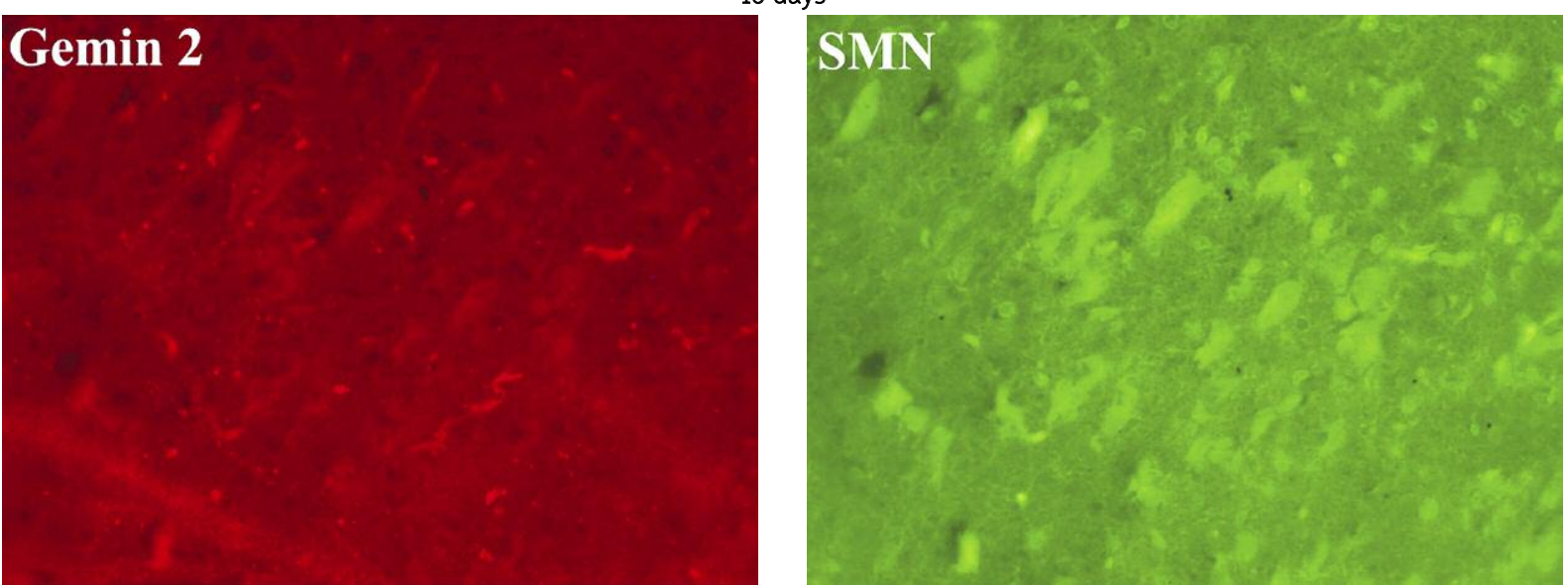

150 days
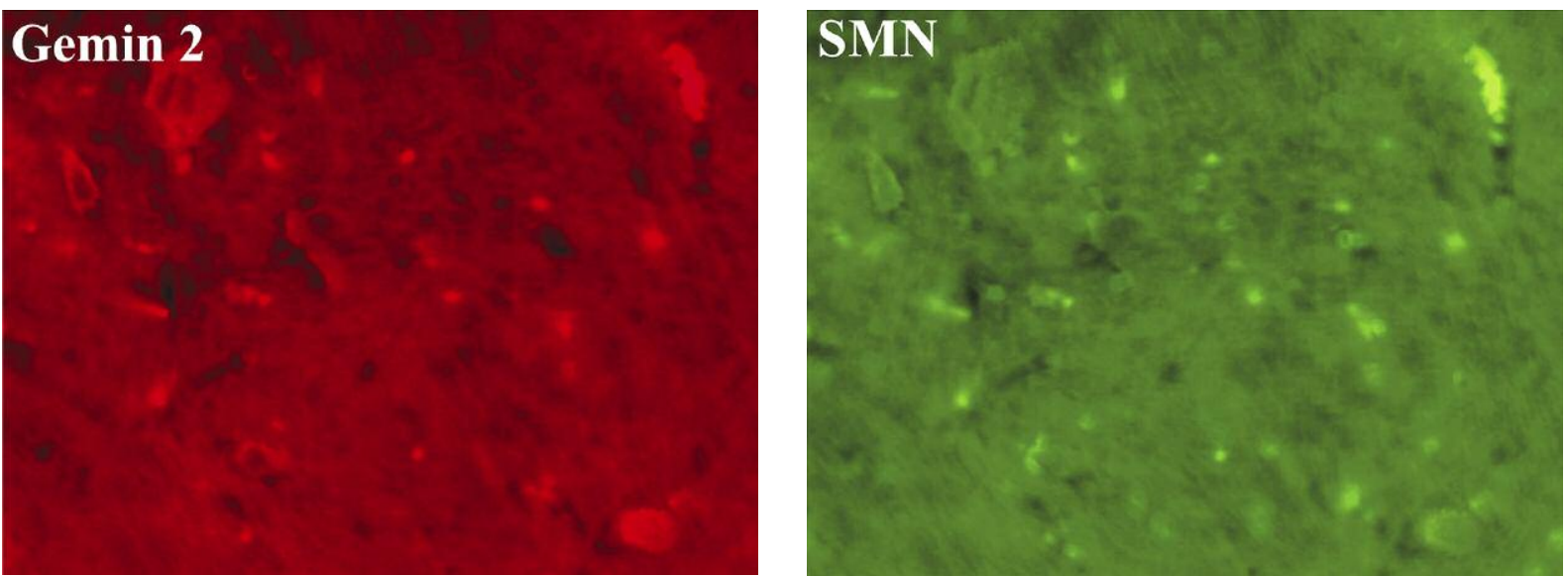

350 days
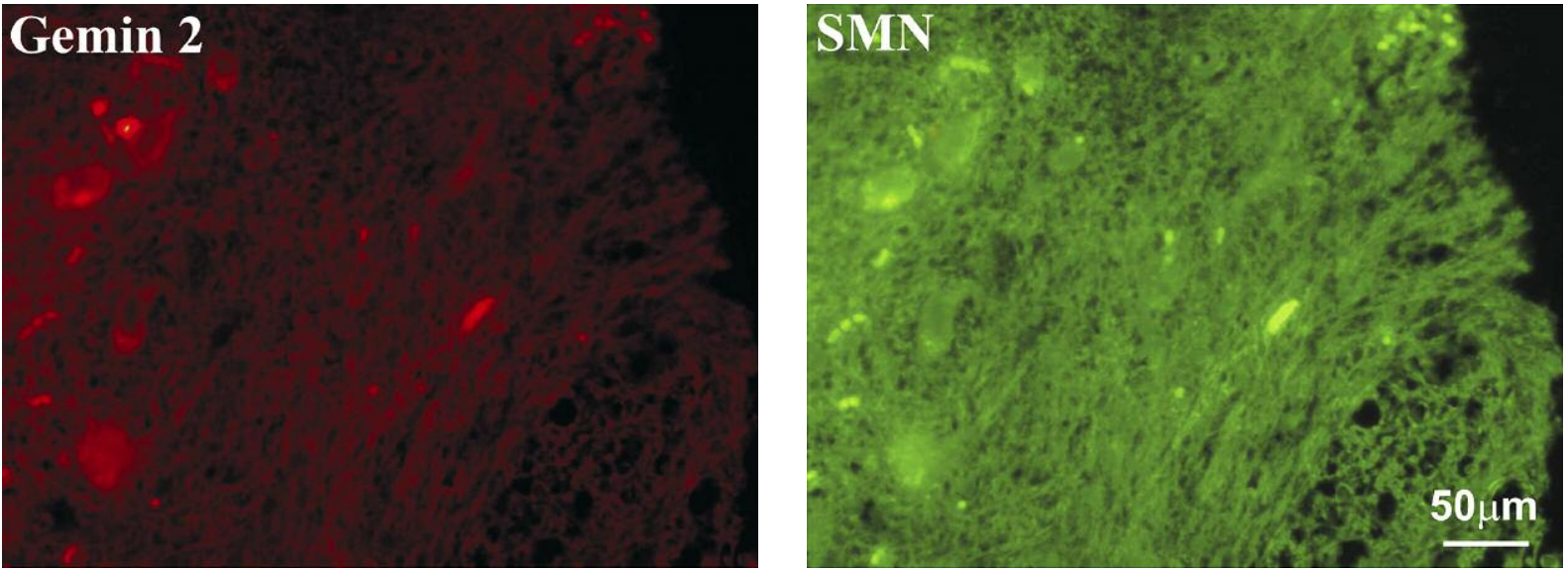

Fig. 3. Double immunofluorescent reaction for gemin 2 and SMN reveals co-expression of the proteins in the same motoneurons.

enhances the disease progression [20]. Deficiency of the SMN protein also causes severity of sporadic ALS [21]. In human SALS the level of the SMN protein, which was investigated in anterior horn cells was reduced [18]. Therefore, it seems possible that non mutated SMN gene plays a protective role for motoneurons. But why 

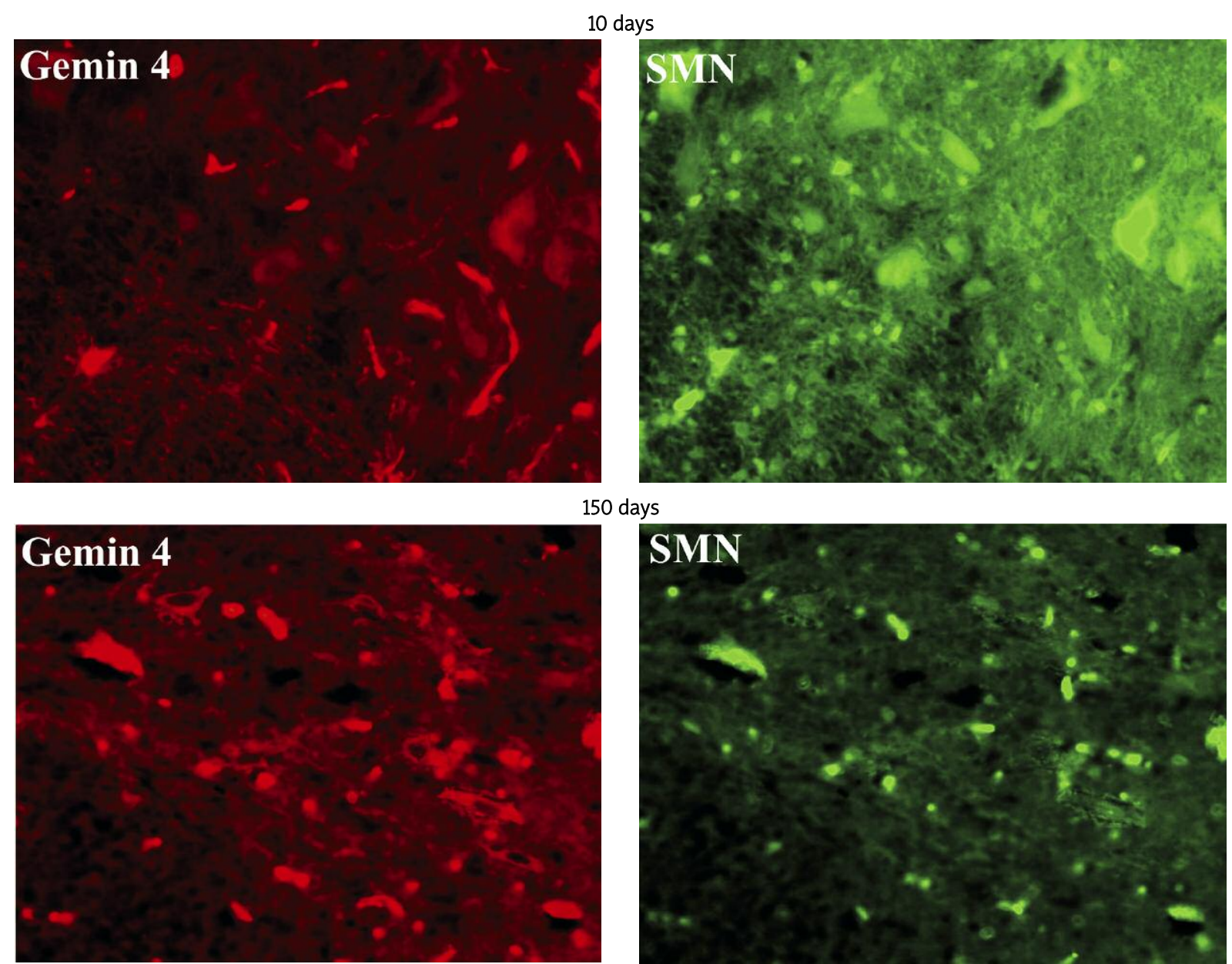

350 days
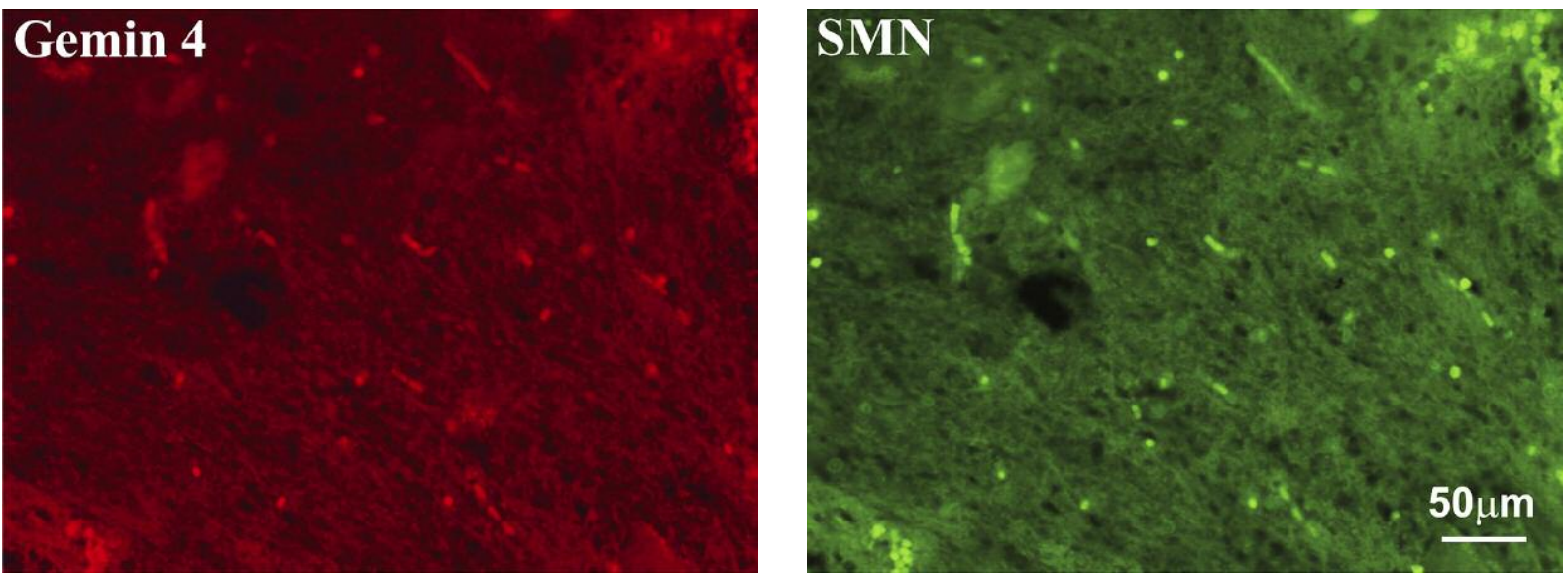

Fig. 4. Double immunofluorescent staining for gemin 4 and SMN shows colocalization of the proteins.

does a normal SMN gene not protect motoneurons in sALS? Perhaps not SMN alone but other compounds of the SMN complex like gemins prevent motoneurons from degenerating.
Although the role of the SMN gene and SMN protein in SALS is intensively investigated there is scarce data in the literature concerning functions of particular gemins in the SMN complex and SALS. Even in 
recently published handbooks [7], reviews [14,22], experimental $[5,15,20]$ and human $[3,18]$ investigations, there are no references concerning that issue. Therefore, we hope that our experimental study on immunoexpression of the selected gemins in healthy rats will initiate a series of investigations on new factors which could participate in very complex pathogenesis of ALS. Such investigations are important because they can offer novel opportunities to understand this dramatic disease.

\section{Acknowledgments}

This study was supported by the Ministry of Science and Higher Education grant NN 401014640.

\section{References}

1. Cauchi RJ, Sanchez-Pulido L, Liu JL. Drosophila SMN complex proteins Gemin2, Gemin3, and Gemin5 are components of $U$ bodies. Exp Cell Res 2010; 316: 2354-2364.

2. Charroux B, Pellizzoni L, Perkinson RA, Yong J, Shevchenko A, Mann M, Dreyfuss G. Gemin 4: a novel component of the SMN complex that is found in both gems and nuclei. J Cell Biol 2000; 148: 1177-1186.

3. Corcia P, Camu W, Halimi JM, Vourc'h P, Antar C, Vedrine S, Giraudeau B, de Toffol B, Andres CR; French ALS Study Group. SMN1 gene, but not SMN2, is a risk factor for sporadic ALS. Neurology 2006; 67: 1147-1150.

4. Corcia P, Camu W, Praline J, Gordon PH, Vourch P, Andres C. The importance of the SMN genes in the genetics of sporadic ALS. Amyotroph Lateral Scler 2009; 10: 436-440.

5. Gertz B, Wong M, Martin LJ. Nuclear localization of human SOD1 and mutant SOD1-specific disruption of survival motor neuron protein complex in transgenic amyotrophic lateral sclerosis mice. J Neuropathol Exp Neurol 2012; 71: 162-177.

6. Giavazzi A, Setola V, Simonati A, Battaglia G. Neuronal-specific roles of the survival motor neuron protein: evidence from survival motor neuron expression patterns in the developing human central nervous system. J Neuropathol Exp Neurol 2006; 65: 267-377.

7. Greenfield Neuropathology. Love S, Louis D, Ellison D (eds.). $8^{\text {th }}$ ed. Oxford University Press, Oxford 2008.

8. Hao le T, Fuller HR, Lam le T, Le TT, Burghes AH, Morris GE. Absence of gemin 5 from SMN complexes in nuclear Cajal bodies. BMC Cell Biol 2007; 18: 8-28.

9. Kolb SJ, Battle DJ, Dreyfuss G. Molecular Functions of the SMN Complex. J Child Neurol 2007; 22: 990-994.

10. La Bella V, Cisterni C, Salaün D, Pettman B. Survival motor neuron (SMN) protein in rat is expressed as different molecular forms and is developmentally regulated. Eur J Neurosci 1998; 10: $2913-$ 2923.

11. Lorson MA, Dickson AM, Shaw DJ, Todd AG, Young EC, Morse R, Wolstencroft C, Lorson CL, Young PJ. Identification and characterisation of a nuclear localisation signal in the SMN associated protein, Gemin4. Biochem Biophys Res Commun 2008; 375: 33-37.
12. Lührmann R, Kastner B, Bach M. Structure of spliceosomal snRNPs and their role in pre-mRNA splicing. Biochim Biophys Acta 1990; 1087: 265-292.

13. Lutz CM, Kariya S, Patruni S, Osborne MA, Liu D, Henderson CE, Li DK, Pellizzoni L, Rojas J, Valenzuela DM, Murphy AJ, Winberg ML, Monani UR. Postsymptomatic restoration of SMN rescues the disease phenotype in a mouse model of severe spinal muscular atrophy. J Clin Invest 2011; 121: 3029-3041.

14. Naganska E, Matyja E. Amyotrophic lateral sclerosis - looking for pathogenesis and effective therapy. Folia Neuropathol 2011; 49: 1-13.

15. Naganska E, Taraszewska A, Matyja E, Grieb P, Rafalowska J. Neuroprotective effect of erythropoietin in amyotrophic lateral sclerosis (ALS) model in vitro. Ultrastructural study. Folia Neuropathol 2010; 48: 35-44.

16. Ogawa C, Usui K, Aoki M, Ito F, Itoh M, Kai C, Kanamori-Katayama M, Hayashizaki Y, Suzuki H. Gemin 2 plays an important role in stabilizing the survival of motor neuron complex. J Biol Chem 2007; 282: 11122-11134.

17. Pellizzoni L, Charroux B, Dreyfuss G. SMN mutants of spinal muscular atrophy patients are defective in binding to snRNP proteins. Proc Natl Acad Sci USA 1999; 96: 11167-11172.

18. Piao Y, Hashimoto T, Takahama S, Kakita A, Komori T, Morita T, Takahashi H, Mizutani T, Oyanagi K. Survival motor neuron (SMN) protein in the spinal anterior horn cells of patients with sporadic amyotrophic lateral sclerosis. Brain Res 2011; 1372: 152-159.

19. Rafalowska J, Sulejczak D, Gadamski R, Dziewulska D. Survival motor neuron (SMN) - a motor neuron insurance for a whole lifespan? Folia Neuropathol 2011; 49: 301-310.

20. Turner BJ, Parkinson NJ, Davies KE, Talbot K. Survival motor neuron deficiency enhances progression in an amyotrophic lateral sclerosis mouse model. Neurobiol Dis 2009; 34: 511-517.

21. Veldink JH, Kalmijn S, Van der Hout AH, Lemmink HH, Groeneveld GJ, Lummen C, Scheffer H, Wokke JH, Van der Berg LH. SMN genotypes producing less SMN protein increase susceptibility to and severity of sporadic ALS. Neurology 2005; 65: 820-825.

22. van Blitterswijk M, Landers JE. RNA processing pathways in amyotrophic lateral sclerosis. Neurogenetics 2010; 11: 275-290.

23. Zhang H, Xing L, Rossoll W, Wichterle H, Singer RH, Bassell GJ. Multiprotein complexes of the survival of motor neuron protein SMN with Gemins traffic to neuronal processes and growth cones of motor neurons. J Neurosci 2006; 26: 8622-8632.

24. Zou T, Ilangovan R, Yu F, Xu Z, Zhou J. SMN protects cells against mutant SOD1 toxicity by increasing chaperone activity. Biochem Biophys Res Commun 2007; 364: 850-855. 